\title{
The reliability of the ankle brachial index: a systematic review
}

\author{
Sarah Casey $^{1^{*}}$ D, Sean Lanting ${ }^{1}$, Christopher Oldmeadow ${ }^{2}$ and Vivienne Chuter ${ }^{1}$
}

\begin{abstract}
Background: The ankle brachial index (ABI) is widely used in clinical practice as a non-invasive method to detect the presence and severity of peripheral arterial disease (PAD). Current guidelines suggest that it should be used to monitor potential progression of PAD in affected individuals. As such, it is important that the test is reliable when used for repeated measurements, by the same or different health practitioners. This systematic review aims to examine the literature to evaluate the inter- and intra-rater reliability of the ABI.

Methods: A systematic search of MEDLINE, EMBASE and CINAHL Complete was conducted to 20 January 2019. Two authors independently reviewed and selected relevant studies and extracted the data. Methodological quality was determined using the Quality Appraisal of Reliability (QAREL) Checklist.
\end{abstract}

Results: Fifteen studies of ABI reliability in a range of patient populations were identified as suitable for inclusion in the review: seven considered inter-rater reliability, four intra-rater reliability, and four studies evaluated both interand intra-rater reliability. Inter-rater reliability was found to be highly variable, with intraclass correlation coefficients (ICC's) ranging from poor to excellent (ICC 0.42-1.00), while intra-rater also demonstrated considerable variation, with ICCs from 0.42-0.98. Meta-analysis was not possible due to the lack of statistical information reported.

Conclusions: Results of included studies suggest the inter- and intra-tester reliability of the $A B I$ is acceptable. However, inconsistencies in obtaining systolic pressure measurements, calculating ABI values, and incomplete reporting of methodologies and statistical analysis make it difficult to determine the validity of the results of included studies. Further research, with more consistent reliability methodology, statistical analysis and reporting conducted in populations at risk of PAD is needed to conclusively determine the ABI reliability.

Keywords: Ankle brachial index, Peripheral arterial disease, Lower extremity artery disease, Repeatability, Reproducibility, Reliability

\section{Introduction/background}

Peripheral arterial disease (PAD) describes the process of progressive atherosclerosis affecting arteries, most frequently in the lower limb. The prevalence in the general population has been estimated at up to $19 \%$ in people over the age of 55 years [1], with incidence increasing with advancing age and in the presence of smoking, inactivity and obesity $[1,2]$. The presence of PAD is associated with increased risk of mortality and morbidity from cardiac atherosclerosis [2], and, in its advanced stages, can result in lower extremity ulceration and amputation [3]. Diabetes mellitus is an independent risk

\footnotetext{
* Correspondence: Sarah.Casey@newcastle.edu.au

${ }^{1} \mathrm{PO}$ Box 127, Ourimbah, NSW 2258, Australia

Full list of author information is available at the end of the article
}

factor for the development of PAD [4], and in people with diabetes, atherosclerotic plaques tend to have a more distal and diffuse distribution and there is a more aggressive disease presentation [5].

Due to the high risk of concurrent cardiovascular morbidity, mortality and lower limb complications associated with PAD, accurate and reliable diagnostic testing methods are required for screening and ongoing monitoring $[2,6]$. Early detection of PAD allows for intervention and management to reduce the risk of mortality and morbidity related to atherosclerosis (lifestyle modification, pharmacotherapy, e.g. statins, antiplatelets, and measures to address systemic risk factors such as hypertension or diabetes) [7]. Current recommendations for non-invasive lower limb vascular assessment include using the ankle-brachial index (ABI) as

(c) The Author(s). 2019 Open Access This article is distributed under the terms of the Creative Commons Attribution 4.0 International License (http://creativecommons.org/licenses/by/4.0/), which permits unrestricted use, distribution, and 
an objective measurement of peripheral blood flow [7, 8]. The ABI represents the ratio of ankle to brachial systolic pressure and is recommended to be calculated by dividing the higher systolic pressure of the dorsalis pedis and tibialis posterior vessels at the ankle with the higher of the systolic pressures measured in the brachial artery in both arms $[7,8]$.

The ABI is widely used to screen for PAD in different clinical settings and by different health professionals, from general medical practitioners to specialist vascular technicians $[9,10]$. Reliability of the test for accurate ongoing monitoring of lower limb vascular status has the potential to be affected by a number of factors. As an operatordependent test, this includes the experience and skills of the clinician, particularly as multiple clinicians are frequently involved in ongoing monitoring measurements $[11,12]$. There are also a number of types of equipment (e.g. automated versus manual) and methods used to measure ankle and arm blood pressures (e.g. stethoscope, Doppler, photoplethysmography probe), with variable findings as to whether the results are interchangeable [13-16]. The pre-test protocol and test environment have also been demonstrated to affect the resting $\mathrm{ABI}$ at measurement, with variations in body position [17], recency of tobacco smoking, caffeine intake [18, 19] and exercise [20, 21], and pre-measurement rest time [22] all likely to introduce error to the measurement and affect the test-retest reliability.

\section{Objectives}

Given that the $\mathrm{ABI}$ is the recommended method for screening for the presence and progression of PAD, it is important that it is reliable. Therefore, the aim of this review was to systematically evaluate the literature to determine the interand intra-rater reliability of the $\mathrm{ABI}$ in adults.

\section{Methods}

\section{Search strategy}

A search of relevant biomedical journal databases from the University of Newcastle library website was performed to identify studies that consider the reliability of ABI measurement from database inception to January 2019 using MEDLINE (1946+), EMBASE (1947+), and CINAHL Complete. Truncated versions of some search terms were used to ensure that relevant studies were included (Table 1).

\section{Inclusion and exclusion criteria}

The review was conducted with reference to the Preferred Reporting Items for Systematic Review and MetaAnalysis (PRISMA) statement [23]. The following criteria had to be satisfied for inclusion in the review: published original research evaluating the reliability of the ABI in adults. Studies were excluded if the test-retest time frame made it likely that results may be affected by
Table 1 Search terms: searches were limited to human studies Databases: MEDLINE (1946+), EMBASE (1947+), and CINAHL Complete

\begin{tabular}{ll}
\hline 1 & Ankle brachial pressure \\
2 & Ankle arm pressure \\
3 & Ankle brachial ind* \\
4 & Reliab* \\
5 & Consistenc* $^{*}$ \\
6 & Accura* \\
7 & Reproduc* $^{*}$ \\
8 & Repeat $^{*}$ \\
9 & Agreement \\
10 & Precision \\
11 & 1 or 2 or 3 AND 4 or 5 or 6 or 7 or 8 or 9 or 10 \\
\hline
\end{tabular}

disease progression e.g. $>12$ months. No language restrictions were applied to the database searches.

\section{Other sources}

Hand searching of the reference list of appropriate articles was also conducted.

\section{Data collection and analysis}

All abstracts obtained were assessed independently by SC and SL for inclusion. There were no instances of disagreement between reviewers, so arbitration by a third person (VC) was not necessary. Data extraction was performed by SC and SL. It was pre-determined that a meta-analysis of reliability outcomes for inter- and intra-rater reliability would be conducted provided there were sufficient studies that report the estimator of interest, and a measure of uncertainty for this estimator (e.g. standard error, 95\% confidence interval, non-truncated $p$-value). Given the expectation for a high degree of study heterogeneity, we believed a fixed effect meta-analysis would generally not be appropriate so we aimed to only pool estimates using a random effects approach provided there were at least 5 studies [24].

\section{Methodological quality assessment}

The studies that met the inclusion criteria were appraised for risk of bias using the Quality Appraisal of Reliability (QAREL) Checklist and qualitative methodological assessment [25]. All full-text papers were assessed for methodological quality independently by two reviewers (SC/SL), and as there were no disagreements arbitration by a third reviewer (VC) was not necessary.

\section{Results}

A total of 1703 articles were retrieved, of which 36 were identified as suitable for full-text review. Twenty-one papers were excluded based on the exclusion criteria (Fig. 1): 10 papers reported comparison of methods [26-35], five 


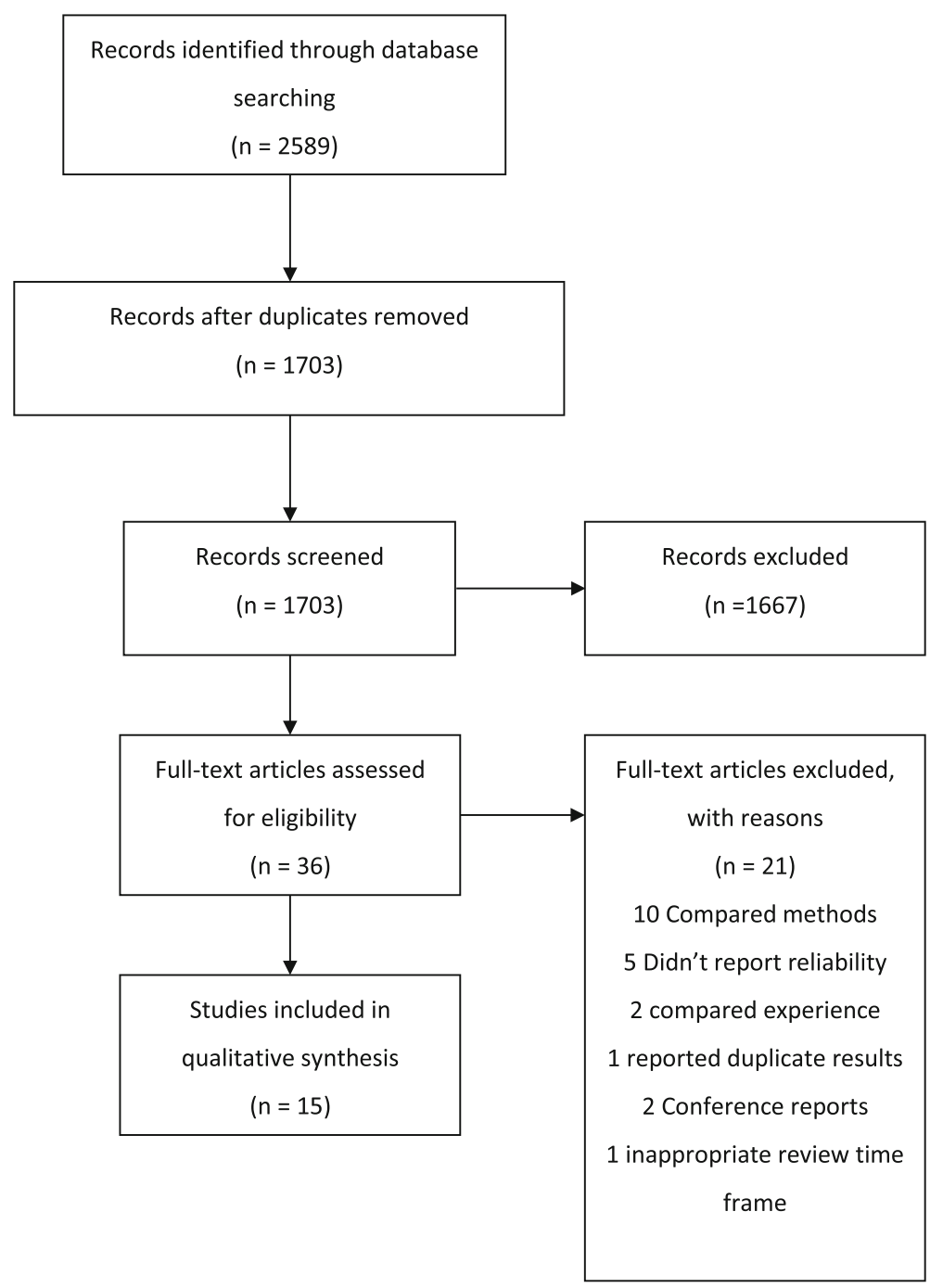

Fig. 1 PRISMA flow chart

studies did not report measures of reliability [36-40], two studies compared raters' experience [41, 42] and one reported a novel trial design, for which the reliability results were duplicated in another included paper [43]. One paper used measures repeated at up to 365 days apart, with a mean time between measures of 228 days, which is long enough to encompass changes attributable to progression of PAD [44]. Two papers were conference abstracts, for which the full text could not be obtained as the authors did not respond to a request for further information $[40,45]$.

Of the included papers, seven measured inter-tester reliability [12, 46-51], four assessed intra-tester reliability [52-55], and four considered both inter- and intra-tester reliability $[13,16,56,57]$.

\section{Characteristics and overview of included studies}

The 15 studies in this review included a total of 916 participants, with data collected from a combination of one and both lower limbs (1396 limbs in total). Two studies did not state the number of limbs included [52, 53]. Eleven studies assessed inter-rater reliability [12, 13, 16, $46-50,56,57]$, and eight studies reported intra-rater reliability [13, 16, 52-57]. The characteristics of included studies are described in Table 2. Eleven studies reported participants' gender, with more men $(n=416,56.4 \%)$ overall than women, whilst gender was unreported in four studies [12, 46, 49, 50]. Most of the studies included predominantly older participants (age range (41-92 years) $[12,13,16,47-49,51,53-55,57]$, however two studies recruited only younger adults (age range 22-30 years) $[46,56]$, one study included $18-80$ year olds [52] and one study did not report participants' ages [50]. The majority of studies [12, 47-51, 55, 57] included only participants with suspected PAD, or risk factors for atherosclerosis; three studied a mixed population including those without risk factors or clinical indicators of PAD 


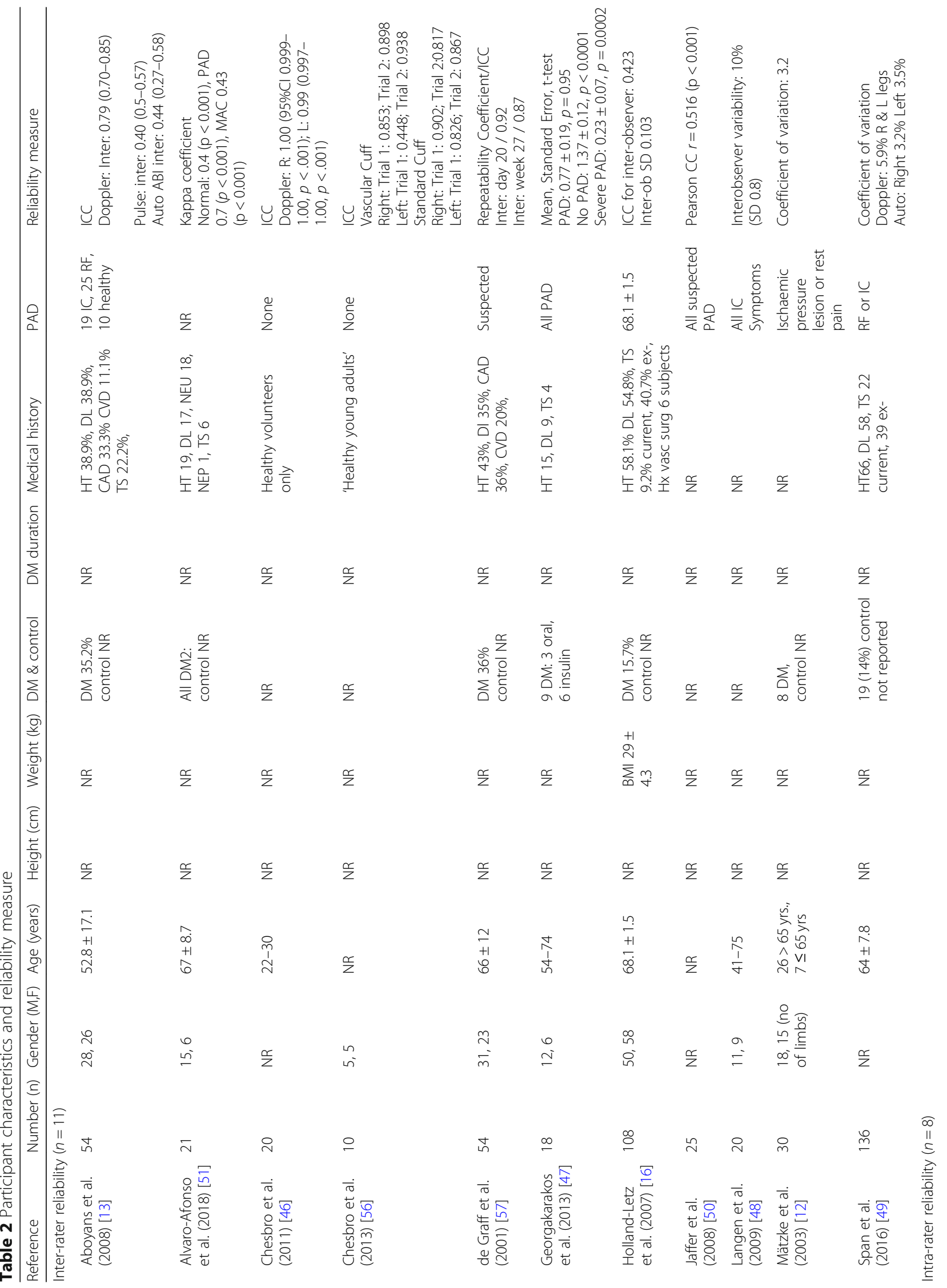




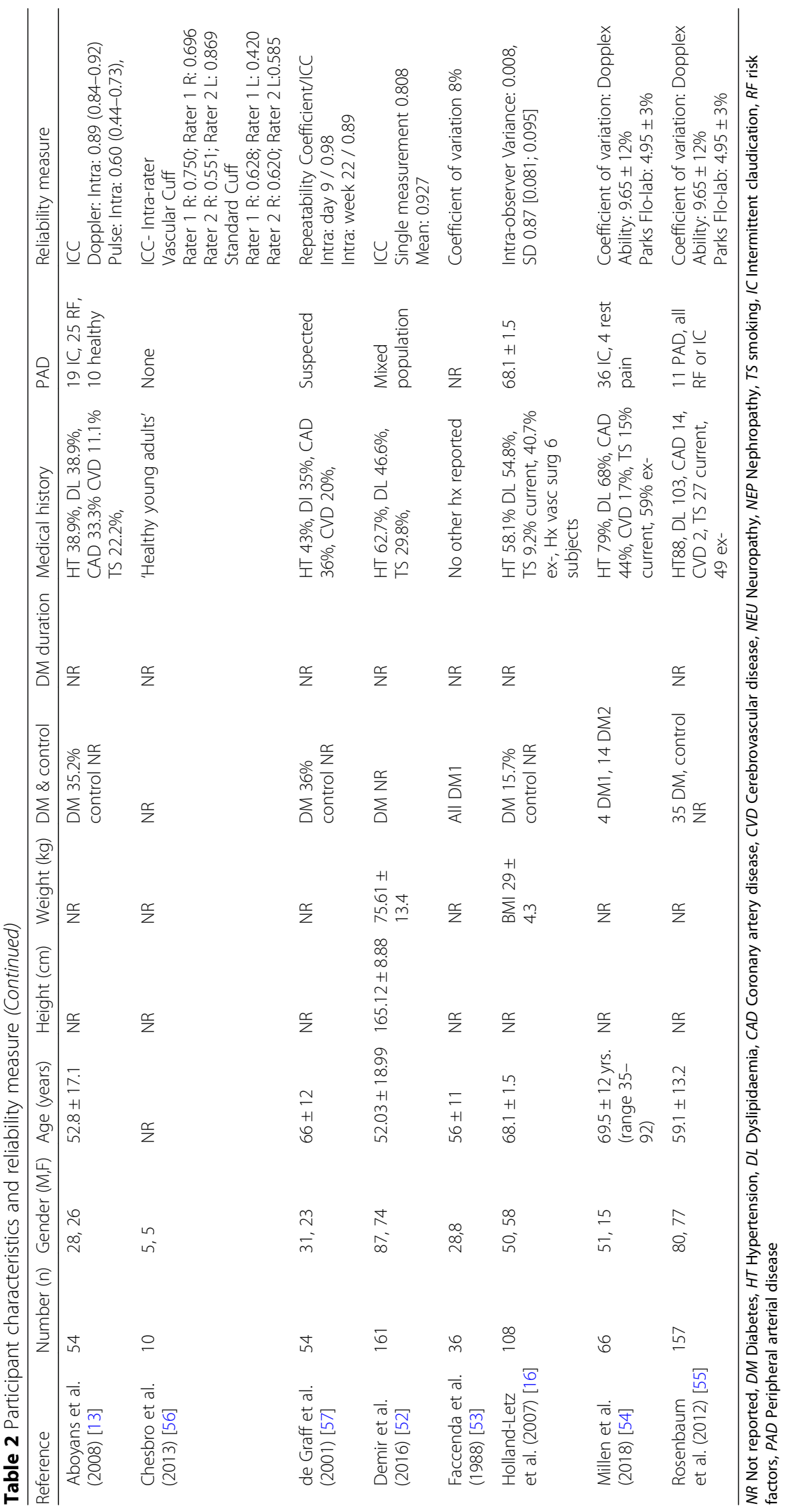


$[13,16,52]$; two studies included only participants with diabetes [53, 54], and two studies included only healthy individuals $[46,56]$.

There was little consistency in the training and qualifications of the raters used, with experience ranging from students $[46,47]$ to experienced vascular technicians and/or vascular specialist doctors [12, 13, 48, 54, 57]. Six studies did not state the background of the personnel performing the test $[49,51-53,55,56]$. The majority of the studies used Doppler and manual sphygmomanometer to measure systolic blood pressures; [12, 13, 16, 46$49,51-53,56]$ however three studies used an automated device to obtain some or all of the pressure readings [54, $55,57]$ and one study did not report the method used [50]. The reported pre-measurement rest time varied from five minutes [55] to $15 \mathrm{~min}$ [48], with seven studies not reporting a period of rest before testing commenced $[44,47,49,50,52-54]$. The time between repeat testing varied from five minutes $[46,56]$ to 4 weeks [52]; six studies did not report time between repeated measures [12, 49-51, 54, 55]. Several different methods were used to calculate the ABI. The majority of studies [47-49, 51, $52,56,57]$ divided the highest ankle pressure by the higher brachial pressure measurement, two $[13,16]$ used the highest ankle pressure and the mean brachial value, and one used the lowest ankle pressure and the highest brachial pressure [55]. One study used a fully automated device that calculated the ABI value [54], and four did not state how the ABI was calculated $[12,46,50,53]$.

\section{Methodological quality}

The quality of studies was variable with regard to reported blinding of raters, order of examination and the time between repeated measurements, with no study clearly addressing all of these variables. While most studies used appropriate statistical measures of agreement, reporting of results was frequently incomplete and the true extent of reliability could not be determined (Table 3 ).

\section{Meta-analysis}

A number of the eligible papers identified lacked sufficient data relating to the main outcomes to allow for inclusion in a meta-analysis. For example, the paper by Chesbro et al., [46] provided no details on the intra-rater reliability of measurements taken using a Doppler, which was the main outcome being assessed in this review. Similarly, papers by De Graaff et al., [57] and Demir et al. [52] detailed no measure of variability for the intraclass correlation coefficients (ICC) reported, which is required when pooling results in a meta-analysis. It is not clear whether Chesbro et al. $[46,56]$ used data from the same population in both studies, and the authors did not respond to a request for clarification. Finally, for the paper by Aboyans et al., [13] the type of ICC calculated was not reported, and while pooling of this data would be possible, understanding which ICC was used is preferred to allow for accurate and appropriate calculation of the standard error. As there were only a small number of eligible papers identified we would require data from all articles to allow for appropriate pooling of ICCs. Thus, as a consequence of the small number of papers reviewed and insufficient data reported by several of the papers it was not possible to conduct a meta-analysis as part of this review. None of the authors responded to requests for missing data. A narrative review of results is presented instead.

\section{Inter-rater reliability}

Inter-rater reliability results are included in Table 2. Statistical methods for calculating reliability were inconsistent. Of the eleven included studies, five reported levels of agreement with ICCs $[13,16,46,56,57]$. Of these, only three $[13,46,56]$ reported $95 \%$ confidence intervals, which limits the interpretation of reliability in the context of clinically meaningful results. Based on ICC values alone, inter-rater reliability was highly variable, ranging from poor (ICC: 0.42) [16], to excellent (ICC: 1.0) [46].

Other estimates of reliability reported in included studies were coefficient of variation between raters [12, 49] (ranging from 3.2 to $5.9 \%$ ), inter-observer reliability of $10 \%$ for raters [48], and a moderate Pearson's correlation coefficient of 0.52 in a population with suspected PAD [50].

Of the remaining studies, one demonstrated statistically significant differences in ABI between raters in a population with severe PAD and in those with no disease, which did not occur in those participants with mild to moderate PAD [47], suggesting increased reliability with this disease state. In contrast, another paper reported Kappa coefficients of 0.4 (low agreement) for healthy limbs, 0.7 (good agreement) for limbs with PAD, and 0.43 (moderate agreement) for limbs with medial arterial calcification (MAC) $(p<0.001$ for all values) [51].

\section{Intra-rater reliability}

Intra-rater reliability results are included in Table 2 . Various methods of calculating reliability were used. Of the eight included studies, four reported ICCs [13, 52, $56,57]$, with ICC values ranging from poor (ICC: 0.42 ) [56] to excellent (0.98) [57]. Interpretation of the results was limited again by the fact that not all studies reported 95\% confidence intervals, with only two articles having done so. $[13,56]$. Other estimates of reliability included coefficient of variation [53-55] (range 4.95\% [54] $15.8 \%$ [55]), and an intra-observer variance of $8 \%$ [16].

\section{Discussion}

The findings of this review are that the inter- and intratester reliability of the $\mathrm{ABI}$ across a number of mixed 


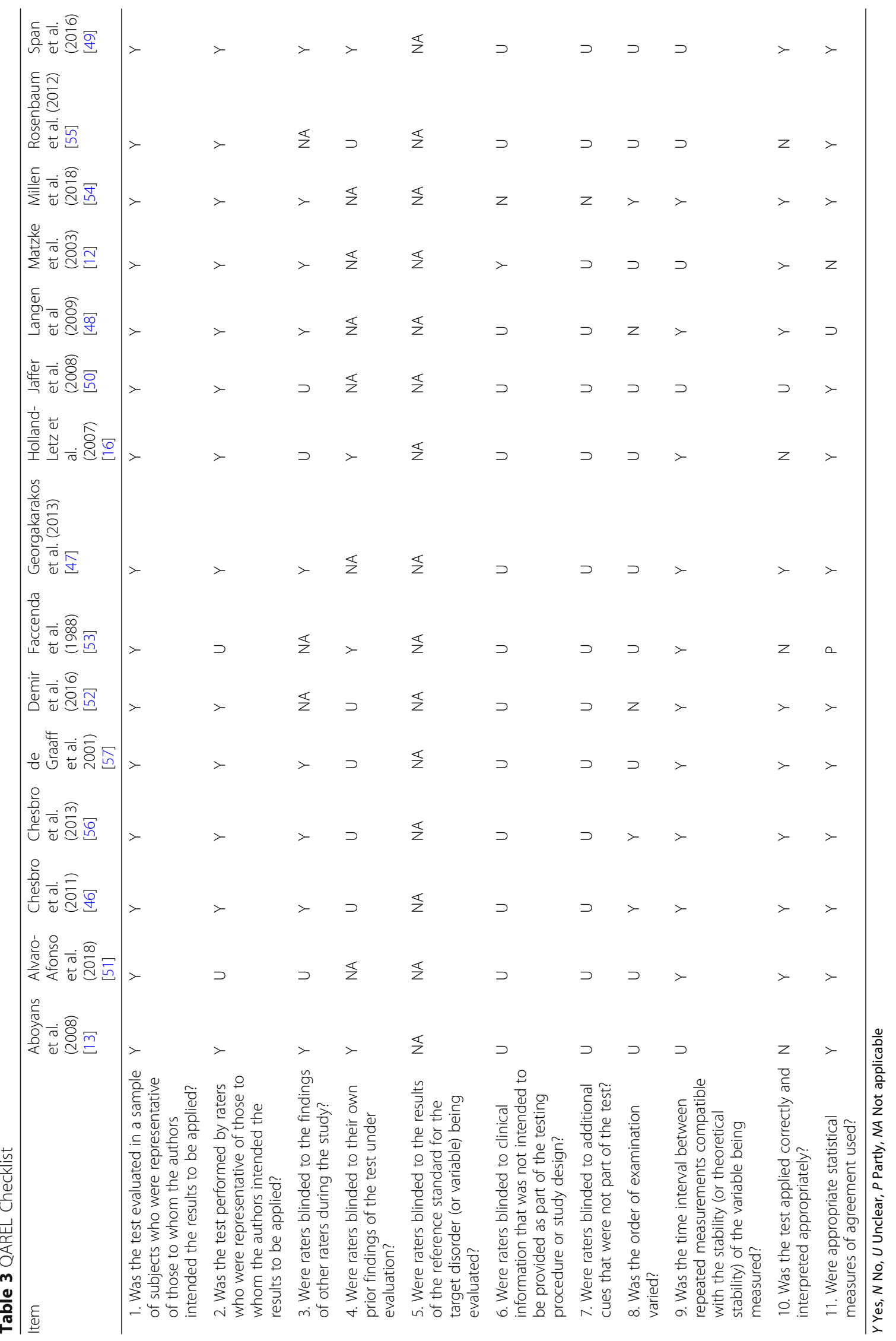


populations appears to be acceptable, however statistical tests of reliability in included papers were heterogeneous and levels of statistical reporting were inconsistent and incomplete. This makes interpretation of the reliability of the $\mathrm{ABI}$ in the context of clinical detection, evaluation and ongoing monitoring of peripheral arterial supply challenging, and prevented meta-analysis. For example, where studies lack $95 \%$ confidence intervals for ICCs, the validity of interpretation of the value is reduced as it fails to provide the lowest level of reliability that it represents. Similarly for coefficient or estimate of variation, values between 3.2 and $15.8 \%$ were reported.. Whilst this is considered an acceptable level of variation for many clinical tests, for the ABI it can represent a range of values that may indicate both normal and pathological results; which could reduce the ability of $\mathrm{ABI}$ to reliably determine the presence and extent of PAD. For example, assuming a variation of $15 \%$, an $\mathrm{ABI}$ of 1.0 (which is considered 'borderline' when $\mathrm{ABI}$ is used as a screening tool [6]) could represent a true value between 0.85 (indicative of PAD) and 1.15 ('normal').

Further complicating the interpretation and generalisability of the inter- and intra-rater reliability results of included studies was the heterogeneity of participant populations. Whilst the majority of studies included older people with PAD risk factors or suspected PAD, three studies also included healthy participants $[13,16$, 52], and two used an exclusively young and healthy population $[46,56]$. In clinical practice, $\mathrm{ABI}$ is used to evaluate peripheral arterial supply in people with risk factors for atherosclerosis, and in those with clinical signs and symptoms of PAD. The variation in the disease status of participants across the studies included in this review provides some difficulty in evaluating how the studies' findings apply to the people in whom the ABI would clinically be used. The study that reported nearperfect inter- and intra- tester reliability included only healthy individuals under the age of 30 [56]. This population would not typically undergo vascular screening, and the results obtained do not indicate the ability of the $\mathrm{ABI}$ to perform reliably in the presence of pathology where the result is likely to be lower and therefore change in result indicative of worsening pathology is likely to be small. In contrast, inter-tester and intratester reliability was found to be poor in several populations in which this test is recommended including people with diabetes and without MAC, [51] and older people with risk factors for PAD [16].

Methodological differences between studies is also likely to have contributed to variable reliability outcomes, with automated oscillometric devices demonstrating marginally better reliability than manual assessment using Doppler $[49,55]$, while Doppler evaluation was found to be more reliable than the use of pulse palpation [13] or stethoscope [46]. Higher ABI reliability was found in more experienced raters [47]. Whilst most of the studies reported that participants rested for $5-15 \mathrm{~min}$ prior to testing [12, 13, 16, 46, $48,51,55-57]$, six studies did not describe any pre-test preparation $[47,49,50,52-54]$, and only one paper took steps to ensure that participants did not consume alcohol, caffeine or tobacco (which are known to affect blood pressure) in the two hours prior to testing which may have affected measurements, particularly when taken across two different testing sessions [55]. This lack of reporting of the methodology used to obtain systolic blood pressure measurements makes it difficult to compare results across the included studies as it is unknown how much external factors are likely to contribute measurement variability.

Two papers identified the presence of diabetes mellitus as a factor that may affect reliability of the $\mathrm{ABI}[12,51]$, however only one study included a large enough sample of this cohort to perform statistical tests [51]. This study, which used only participants with diabetes, reported the Kappa coefficient for inter-tester measures for participants classed as having PAD or not, rather than performing ICCs on the measures obtained. The authors reported 'good' reproducibility of the ABI (K 0.7) in people classified by their $\mathrm{ABI}$ measurement as having PAD, but low reproducibility in those without PAD and in those with MAC. Previous research has also shown that people with diabetes demonstrate a different response to pre-measurement rest [22], and that brachial blood pressure measurement is also less reliable in these individuals [58]. Diabetes-related autonomic neuropathy has been shown to affect blood pressure regulation, with a lack of vasoconstriction arising from reduced sympathetic input, particularly in response to changes in temperature and position $[59,60]$.

\section{Limitations}

While the search methods employed in this study were designed to be robust, there may be some evidence that was not captured, for example unpublished data. Further limitations to this study are the inability to perform metaanalysis in order to obtain a quantitative analysis of the available reliability data for the $\mathrm{ABI}$, and the inability perform any sub-analyses relating to individual populations such as those with diabetes, or methods of measurement such as automated or manual methods. Furthermore, there has been some disagreement in the literature about which pressure measurement should be used to calculate the ABI $[61,62]$, with no studies exploring the effect of calculation method on reliability. However, the method of calculation cannot be excluded as a factor affecting reliability that has not been considered by this review.

\section{Conclusion}

Results of included studies suggest the inter- and intratester reliability of the ABI is acceptable. However, inconsistencies in obtaining systolic pressure measurements, 
calculating $\mathrm{ABI}$ values, and incomplete reporting of methodologies and statistical analysis make it difficult to determine the validity of the results of included studies. Further research of ABI reliability using a more consistent approach to study design and implementation and more detailed reporting of results in populations with vascular pathology and at risk of PAD is required. Based on current available data clinicians should ensure they interpret ABI results in the context of other vascular assessment findings, and patient management is not based upon this measurement alone.

\section{Abbreviations}

ABI: ankle brachial index; IC: intermittent claudication; ICC: intraclass correlation coefficient; MAC: medial arterial calcification; PAD: peripheral arterial disease; QAREL: Quality Appraisal of Reliability

\section{Acknowledgements}

Not applicable.

\section{Availability of data and material}

All data generated or analysed during this study are available in this article.

\section{Authors' contributions}

VC and SC conceived the study. Database searches and data extraction was conducted by SC and SL. Statistical evaluation was performed by CO. All authors contributed to the manuscript and approved the final manuscript.

\section{Funding}

Funding sources include the national Research Training Scheme (Australia).

\section{Ethics approval and consent to participate}

Not applicable.

\section{Consent for publication}

Not applicable.

\section{Competing interests}

The authors declare that they have no competing interests.

\section{Author details}

'PO Box 127, Ourimbah, NSW 2258, Australia. ${ }^{2}$ CReDITSS - HMRI, School of Medicine and Public Health, Newcastle, Australia.

\section{Received: 30 May 2019 Accepted: 29 July 2019}

Published online: 02 August 2019

\section{References}

1. Meijer WT, Hoes AW, Rutgers D, Bots ML, Hofman A, Grobbee DE. Peripheral arterial disease in the elderly. Rotterdam Stud. 1998;18(2):185-92.

2. Norman PE, Eikelboom JW, Hankey GJ. Peripheral arterial disease: prognostic significance and prevention of atherothrombotic complications. Med J Aust. 2004;181(3):150-4.

3. Bonham PA. Get the LEAD out: noninvasive assessment for lower extremity arterial disease using ankle brachial index and toe brachial index measurements. J Wound Ostomy and Continence Nurs. 2006:33(1):30-41.

4. American Diabetes Association. Peripheral arterial disease in people with diabetes. Diabetes Care. 2003:26(12):3333-41.

5. Jude EB, Oyibo SO, Chalmers N, Boulton AJM. Peripheral arterial disease in diabetic and nondiabetic patients: a comparison of severity and outcome. Diabetes Care. 2001;24(8):1433-7.

6. Aboyans V, Criqui MH, Abraham P, Allison MA, Creager MA, Diehm C, et al. Measurement and interpretation of the ankle-brachial index. A Scientific Statement From the American Heart Association. Circulation. 2012;126(24): 2890-909.

7. Gerhard-Herman MD, Gornik HL, Barrett C, Barshes NR, Corriere MA, Drachman DE, et al. 2016 AHA/ACC guideline on the management of patients with lower extremity peripheral artery disease: executive summary.
A Report of the American College of Cardiology/American Heart Association Task Force on Clinical Practice Guidelines 2016.

8. Norgren L, Hiatt WR, Dormandy JA, Nehler MR, Harris KA, Fowkes FGR. Intersociety consensus for the Management of Peripheral Arterial Disease (TASC II). J Vasc Surg. 2007;45(1):S5-S67.

9. Haigh K, Bingley J, Golledge J, Walker P. Peripheral arterial disease -screening in general practice. Aust Fam Physician. 2013;42:391-5.

10. Al-Qaisi M, Nott DM, King DH, Kaddoura S. Ankle brachial pressure index (ABPI): an update for practitioners. Vasc Health Risk Manag. 2009;5:833-41.

11. Nicolai SP, Kruidenier LM, Rouwet EV, Bartelink ML, Prins MH, Teijink JA. Ankle brachial index measurement in primary care: are we doing it right? $\mathrm{Br}$ J Gen Pract. 2009;59(563):422-7.

12. Matzke S, Franckena M, Alback A, Railo M, Lepantalo M. Ankle brachial index measurements in critical leg ischaemia - the influence of experience on reproducibility. Scand J Surg. 2003;92:144-7.

13. Aboyans V, Lacroix P, Doucet S, Preux PM, Criqui MH, Laskar M. Diagnosis of peripheral arterial disease in general practice: can the ankle-brachial index be measured either by pulse palpation or an automatic blood pressure device? Int J Clin Pract. 2008:62.

14. Staessen JA, Li Y, Wang J-G. Comparison of three measures of the anklebrachial blood pressure index in a general population. Hypertens Res. 2007: 30:555.

15. Ramanathan A, Conaghan PJ, Jenkinson AD, Bishop CR. Comparison of ankle-brachial pressure index measurements using an automated oscillometric device with the standard doppler ultrasound technique. ANZ J Surg. 2003;73(3):105-8.

16. Holland-Letz T, Endres HG, Biedermann S, Mahn M, Kunert J, Groh S, et al. Reproducibility and reliability of the ankle-brachial index as assessed by vascular experts, family physicians and nurses. Vasc Med. 2007;12(2):105-12.

17. Pollak EW, Chavis P, Wolfman EF. The effect of postural changes upon the ankle arterial perfusion pressure. Vasc Surg. 1976;10(4):219-22.

18. Pilli R, Naidu M, Pingali U, Takallapally RK. Study of cardiovascular effects of caffeine in healthy human subjects, with special reference to pulse wave velocity using photoplethysmography. Int J Nutr Pharmacol Neurol Dis. 2012;2(3):243-50.

19. Waring WS, Goudsmit J, Marwick J, Webb DJ, Maxwell SR. Acute caffeine intake influences central more than peripheral blood pressure in young adults. Am J Hypertens. 2003:16(11 Pt 1):919-24.

20. Yataco AR, Gardner AW. Acute reduction in ankle/brachial index following smoking in chronic smokers with peripheral arterial occlusive disease. Angiology. 1999;50(5):355-60

21. Carter SA. Response of ankle systolic pressure to leg exercise in mild or questionable arterial disease. N Engl J Med. 1972;287(12):578-82.

22. Chuter VH, Casey SL. Effect of premeasurement rest time on systolic ankle pressure. J Am Heart Assoc. 2013;2(4):e000203.

23. Liberati A, Altman DG, Tetzlaff J, Mulrow C, Gotzsche PC, loannidis JP, et al. The PRISMA statement for reporting systematic reviews and meta-analyses of studies that evaluate health care interventions: explanation and elaboration. PLoS Med. 2009:6:e1000100.

24. Borenstein M, Hedges LV, Higgins JP, Rothstein HR. A basic introduction to fixed-effect and random-effects models for meta-analysis. Res Synth Methods. 2010;1 (2):97-111

25. Lucas NP, Macaskill P, Irwig I, Bogduk N. The development of a quality appraisa tool for studies of diagnostic reliability. J Clin Epidemiol. 2010;63:854-61.

26. Jvd S, Verbogt NP, Mulder PG, Steunenberg SL, Steunenberg BE, Lvd L. The clinical applicability of an automated plethysmographic determination of the ankle-brachial index after vascular surgery. Vascular. 2016;24(5):545-8.

27. Harrison ML, Lin H-F, Blakely DW, Tanaka H. Preliminary assessment of an automatic screening device for peripheral arterial disease using anklebrachial and toe-brachial indices. Blood Press Monit. 2011;16(3):138-41.

28. Khandanpour N, Armon MP, Jennings B, Clark A, Meyer FJ. Photoplethysmography, an easy and accurate method for measuring ankle brachial pressure index: can photoplethysmography replace Doppler? Vasc Endovasc Surg. 2009;43(6):578-82.

29. Bonham PA, Cappuccio M, Hulsey T, Michel Y, Kelechi T, Jenkins C, et al. Are ankle and toe brachial indices (ABI-TBI) obtained by a pocket Doppler interchangeable with those obtained by standard laboratory equipment? J Wound Ostomy Continence Nurs. 2007;34(1):35-44.

30. Raines JK, Farrar J, Noicely K, Pena J, Davis WW, Willens HJ, et al. Ankle/ brachial index in the primary care setting. Vasc Endovasc Surg. 2004; 38(2):131-6. 
31. Gestin S, Delluc A, Saliou AH, Colas A, Guéguen F, Gladu G, et al. Ankle brachial pressure index (ABPI): color-Doppler versus ultrasound Doppler correlation study in 98 patients after analysis of interobserver reproducibility. J Mal Vasc. 2012;37(4):186-94.

32. Kollias A, Xilomenos A, Protogerou A, Dimakakos E, Stergiou GS. Automated determination of the ankle-brachial index using an oscillometric blood pressure monitor: validation vs. Doppler measurement and cardiovascular risk factor profile. Hypertens Res. 2011;34(7):825-30.

33. Hamel J-F, Foucaud D, Fanello S. Comparison of the automated oscillometric method with the gold standard Doppler ultrasound method to access the ankle-brachial pressure index. Angiology. 2010;61(5):487-91.

34. Davies JH, Williams EM. Automated plethysmographic measurement of the ankle-brachial index: a comparison with the doppler ultrasound method. Hypertens Res. 2016;39(2):100-6.

35. Bundó $M$, Urrea M, Muñoz-Ortíz L, Pérez C, Llussà J, Forés R, et al. Measurement of the ankle brachial index with a non-mercury sphygmomanometer in diabetic patients: a concordance study. BMC Cardiovasc Disord. 2013;13(1):1-7.

36. Fowkes FG, Housley E, Macintyre CC, Prescott RJ, Ruckley CV. Variability of ankle and brachial systolic pressures in the measurement of atherosclerotic peripheral arterial disease. J Epidemiol Community Health. 1988;42(2):128-33.

37. Ena J, Lozano T, Verdú G, Argente CR, González VL. Accuracy of anklebrachial index obtained by automated blood pressure measuring devices in patients with diabetes mellitus. Diabetes Res Clin Pract. 2011;92(3):329-36.

38. Chongthawonsatid S, Dutsadeevettakul S. Validity and reliability of the ankle-brachial index by oscillometric blood pressure and automated anklebrachial index. J Res Med Sci. 2017;22:44.

39. Alzamora MT, Baena-Díez JM, Sorribes M, Forés $R$, Toran P, Vicheto M. Peripheral Arterial Disease study (PERART): prevalence and predictive values of asymptomatic peripheral arterial occlusive disease related to cardiovascular morbidity and mortality. BMC Publ Health. 2007;7. https://doi. org/10.1186/1471-2458-7-348

40. Bakalakou K, Marinakos A, Nouli A, Taxiarchou E, Margariti C, Papanikitas K, et al. Efficacy of automatic blood pressure device to determine reliably the ankle brachial index (ABI). Eur J Intern Med. 2011;22:S9.

41. Monti M, Calanca L, Alatri A, Mazzolai L. Accuracy of in-patients anklebrachial index measurement by medical students. Vasa. 2016;45(1):43-8.

42. Nexøe J, Damsbo B, Lund JO, Munck A. Measurement of blood pressure, ankle blood pressure and calculation of ankle brachial index in general practice. Fam Pract. 2012;29(3):345-51.

43. Endres $\mathrm{H}$, Hucke $\mathrm{C}$, Holland-Letz $\mathrm{T}$, Trampisch $\mathrm{H}$-J. A new efficient trial design for assessing reliability of ankle-brachial index measures by three different observer groups. BMC Cardiovasc Disord. 2006;6(1):33.

44. Weatherley BD, Chambless LE, Heiss G, Catellier DJ, Ellison CR. The reliability of the ankle-brachial index in the atherosclerosis risk in communities (ARIC) study and the NHLBI family heart study (FHS). BMC Cardiovasc Disord. 2006; 6(1):1-11.

45. Balkanay OO, Arapi B, Arslan C, Gurel SA. Reliability of ankle brachial index measurement by oscillometric blood pressure monitoring device. Heart Surg Forum. 2012;15:S66.

46. Chesbro SB, Asongwed ET, Brown J, John EB. Reliability of Doppler and stethoscope methods of determining systolic blood pressures: considerations for calculating an ankle-brachial index. J Natl Med Assoc. 2011;103(9):863-9.

47. Georgakarakos E, Papadaki E, Vamvakerou V, Lytras D, Tsiokani A, Tsolakak $\mathrm{O}$, et al. Training to measure ankle-brachial index at the undergraduate level: can it be successful? Int J Low Extrem Wounds. 2013;12(2):167-71.

48. $H \vee L, J v G$, Rubbens $L$. Interobserver variability of ankle-brachial index measurements at rest and post exercise in patients with intermittent claudication. Vasc Med. 2009;14(3):221-6.

49. Špan M, Geršak $G$, Millasseau SC, Meža M, Košir A. Detection of peripheral arterial disease with an improved automated device: comparison of a new oscillometric device and the standard Doppler method. Vasc Health Risk Manag. 2016;12:305-11.

50. Jaffer U, Elmagrabi AW, Cameron A, Osman I. Agreement of communityperformed ankle brachial pressure indices (ABPI) with vascular laboratory performed assessment. Vasc Dis Manag. 2008;5(2):71-2.

51. Alvaro-Afonso FJ, Garcia-Morales E, Molines-Barroso RJ, Garcia-Alvarez Y, Sanz-Corbalan I, Lazaro-Martinez JL. Interobserver reliability of the anklebrachial index, toe-brachial index and distal pulse palpation in patients with diabetes. Diab Vasc Dis Res. 2018;15(4):344-7.
52. Demir O, Tasci I, Acikel C, Saglam K, Gezer M, Acar R, et al. Individual variations in ankle brachial index measurement among Turkish adults. Vascular. 2016;24(1):53-8.

53. Faccenda F, Rubba P, Vaccaro O, Carbone L, Pauciullo P, Riccardi G. Reproducibility of non-invasive vascular diagnosis in patients with diabetes mellitus. Artery. 1989;16(4):189-207.

54. Millen RN, Thomas KN, Majumder A, Hill BG, Van Rij AM, Krysa J. Accuracy and repeatability of the Dopplex Ability. Expert Review of Medical Devices. 2018;15(3):247-51.

55. Rosenbaum D, Rodriguez-Carranza S, Laroche P, Bruckert E, Giral P, Girerd X. Accuracy of the ankle-brachial index using the $\mathrm{SCVL}\left({ }^{\circledR}\right)$, an arm and ankle automated device with synchronized cuffs, in a population with increased cardiovascular risk. Vasc Health Risk Manag. 2012;8:239-46.

56. Chesbro SB, Asongwed ET, John EB, Haile N. Reliability of ankle-brachial index measurements: a comparison of standard and vascular blood pressure cuffs. Top Geriatr Rehabil. 2013;29(3):195-202.

57. de Graaff JC, Ubbink DT, Legemate DA, de Haan RJ, Jacobs MJHM. Interobserver and intraobserver reproducibility of peripheral blood and oxygen pressure measurements in the assessment of lower extremity arterial disease. J Vasc Surg. 2001;33(5):1033-40.

58. Sonter JA, Chuter V, Casey S. Intratester and intertester reliability of toe pressure measurements in people with and without diabetes performed by podiatric physicians. J Am Podiatr Med Assoc. 2015;105(3):201-8.

59. Christensen NJ. Spontaneous variations in resting blood flow, postischaemic peak flow and vibratory perception in the feet of diabetics. Diabetalogia. 1969:5(3):171-8

60. Hilsted J, Parving HH, Christensen NJ, Benn J, Galbo H. Hemodynamics in diabetic orthostatic hypotension. J Clin Invest. 1981;68(6):1427-34.

61. Schröder F, Diehm N, Kareem S, Ames M, Pira A, Zwettler U, et al. A modified calculation of ankle-brachial pressure index is far more sensitive in the detection of peripheral arterial disease. J Vasc Surg. 2006;44(3):531-6.

62. Niazi K, Khan TH, Easley KA. Diagnostic utility of the two methods of ankle brachial index in the detection of peripheral arterial disease of lower extremities. Catheter Cardiovasc Interv. 2006;68(5):788-92.

\section{Publisher's Note}

Springer Nature remains neutral with regard to jurisdictional claims in published maps and institutional affiliations.
Ready to submit your research? Choose BMC and benefit from:

- fast, convenient online submission

- thorough peer review by experienced researchers in your field

- rapid publication on acceptance

- support for research data, including large and complex data types

- gold Open Access which fosters wider collaboration and increased citations

- maximum visibility for your research: over $100 \mathrm{M}$ website views per year

At $\mathrm{BMC}$, research is always in progress.

Learn more biomedcentral.com/submissions 